\title{
The Voice of the Hijab: Perspectives towards Wearing the Hijab by a Sample of Palestinian Female University Students in Israel
}

\author{
By Omar Mizel*
}

\begin{abstract}
The question of the meaning of the hijab surfaces time and again, as various parties raise issues about its relationship with Islam and other faiths. Notions including liberty, terrorism, persecution, fanaticism, and democracy are addressed, among many others. It has been recently noted that the number of Palestinian university female students (PUFS) wearing the hijab is on the rise. This study seeks to explore the reasons behind this behavioural phenomenon and to understand how PUFS wearing the hijab view the hijab. It seeks to answer two central questions: "How do these female students justify their choice of wearing the hijab?", and "How do these justifications differ according to their socio-educational context?" The study consists of 25 in-depth interviews with female students studying at a mixed academic college of Arab and Jewish students. The study revealed that the perception and justification for wearing the hijab is not only religious; the hijab also expresses social, cultural, economic, and political perceptions. The traditional notion of the hijab as a means of oppressing a woman's freedom is no longer valid. On the contrary, PUFS indicate that wearing the hijab harmonises with modernisation and contributes to Moslem women's adaptation, wherever they are, serving as an essential factor for their engagement with society.
\end{abstract}

Keywords: Hijab, University, Palestine, Israel, Islam

\section{Introduction}

Several studies indicate that the phenomenon of women donning the hijab is one of the most ancient social phenomena. Both in Judaism and Christianity, the head covering has long been an expression of commitment to religious and moral obligations. In Islam, the hijab is considered a social and moral regulator that gives a woman respect, and protects her chastity and livelihood. Recently, it has attained a social value, and become a symbol of culture and identity. Undoubtedly, wearing the hijab was a religious obligation and a moral necessity and commitment before it became a social behaviour and a cultural practice. It is absolutely non-negotiable and irreplaceable in terms of form and design, as is the case for contemporary fashions. Even if the hijab undergoes some modifications, it still abides by the general framework dictated by religious regulations and teachings. However, it has been recently noticed that the hijab has become a tool to promote different tastes as well as modern design tendencies. Such practices often push the hijab towards becoming a fashion item.

Hijab-wearing women engender a huge dilemma for many people, and there are varying views regarding this topic. Some consider it an obstacle placed before a woman in attaining her liberty and humanity. A second party views it from a

${ }^{*}$ Head of Academic Education Department, Ono Academic College, Israel. 
religious standpoint that makes it impossible to reject, or in fact express any opinion about it. The first party indicates that the hijab was linked to a specific period that ended with the end of the Prophet's time. It was not required of all Muslim women, but was limited to prophets' wives. Not wearing the hijab was not considered a grave sin that leads to hell, but rather a minor transgression forgivable by God the Almighty (Mussap, 2009; Swami 2012).

Supporters of the second opinion can in turn be divided into two groups: the first completely believe Islamic teachings and strictly wear the hijab in observation of God's verse: "Wama kana limuminin wala muminatin itha qada Allahu warasooluhu amran an yakoona lahumu alkhiyaratu min amrihim waman yaAAs $i$ Allaha warasoolahu faqad dalla dalalan mubeenan" ["It is not fitting for a Believer, man or woman, when a matter has been decided by Allah and His Messenger to have any option about their decision: if anyone disobeys Allah and His Messenger, he is indeed on a clearly wrong path"] (Holy Quran, chapter Al Ahzab, verse 36). As for the second group, they are reluctant to abide by God's teachings and are unable to implement his orders for a number of reasons (Mahfoodh 2008):

- Weak belief in God the Almighty

- Ignorance of religious teachings and orders

- The concept of the hijab is associated with intellectual misconceptions resulting from customs and traditions (Abdallah 2011)

Various forms of cloth covering are used by Moslem women. They vary in their degree of covering, and include the hijab, which covers the head and neck; the niqab, which also covers the face but not the area around the eyes; the khimar, that covers the head and continues down to the waist; and the burka, that covers the whole face and body.

This study focuses on the hijab. For the purpose of this study, the hijab is defined as a garment that covers the woman's head. The hijab is used nowadays to refer to a piece of cloth that women use to cover their hair. They tie it down the neck or use pins to fit it, but they keep their face uncovered. Its precise shape differs according to social and geographical requirements and traditions. As viewed by sociologists, the hijab is one of social traditions that are considered part of the social and cultural elements. Some researchers hold the view that the hijab is crucial for the fulfilment of social belonging and security in Moslem societies (Swami 2012, Siraj 2011).

Recent decades have witnessed a powerful return of the hijab in the Palestinian society in Israel. This return is distinguished by the fact that many university and college female students wear the hijab. Consequently, interest in studying this phenomenon has increased. Some studies (Latifi 2006; Shawish 2002) indicate that there are two rationales that lead to wearing the hijab. There is the religious rationale, of course; the second type of rationale for hijab-wearing is related to individual decisions which might be based on social, psychological, economic, and other considerations.

Faisal (2004) explained that wearing the hijab does not carry a single significance. Some categorize it under religious rubrics, while others refer to a 
completely different set of variables that are mainly political, yet wrapped in religion (Faisal 2004). Faisal claimed that there has been a social dimension for wearing the hijab, especially in recent years. The social aspect has influenced the shape and quality of the hijab, leading to the traditional religious hijab, modern hijab, fashionable hijab, political symbol hijab, tribal hijab, and others. These other reasons for wearing the hijab stem from a philosophical perspective, as it gives value to humanism that originates in the existence of the human being, as well as taking into consideration the significance of values, principles, customs, and traditions (Khan et al. 2005).

Other social aspects of wearing the hijab relate to marriage -indeed, this has become one of the important reasons for hijab-wearing among unmarried girls. Latifi (2006) explained that, "Marriage became an ambition for several girls who were competing to find their future husbands". Accordingly, we understand that the hijab signifies the high morals and commitment of the woman or girl who wears it. Al Hufi (2006) indicated that there was another social aspect for wearing hijab, linked to poverty. The hijab in many cases would be a simple solution to make up for the girl's inability to keep up with new and fashionable clothes (Al Hufi 2006, Witkowski 1999).

In the Arab world, empirical studies were conducted to identify why the hijab spread among university female students. One study, conducted in Iraq by Shahba Khazal (2006), concluded that students wore the hijab for mainly social rather than religious factors. The social aspect included parents' influence and physical beauty to attract admiration. A very low percentage wore the hijab out of decency, chastity, or to conceal their beauty. Interestingly, shop window displays also had a great impact on making girls wear the hijab. The percentage of those influenced by this variable reached $45 \%$.

The same study by Khazal (2006) found that the hijab represented one of the manifestations of Islamic thought; it was applied to show the border line between the message of Muslims and that of secular people. The study stressed that the hijab was not confined to Muslims; in fact, other peoples also use it. The most ancient people who subjected women to the hijab were the Assyrians (Syriacs). The study emphasized that other monotheistic religions such as Judaism and Christianity also require using a similar article of clothing to the hijab for religious activities.

In a field study, Al Akhras (1967) interviewed a sample of 400 females from Damascus City and its surroundings, of which 180 were married. The study showed that $44 \%$ of married women wore the hijab when they went outside their homes while $7 \%$ of them wore religious hijab all the time. In Egypt, the researcher Radwan (1984) conducted a study to identify why Egyptian university female students wore the hijab. He found that the majority of hijab-wearers come from middleclass families and believe less in women's right to education and work. Ninety-four percent of hijab-wearers reject women's work outside her home country because of prevailing customs, traditions, and the requirement of having a mahram (escort) with her. 


\section{Theoretical Framework}

The theoretical framework for this research derives primarily from symbolic interactionism. The term "symbolic interactionism" was originally coined by Blumer (1962). Human beings act toward things on the basis of the meanings they ascribe to these things:

1. The meaning of things derives from social interactions.

2. These meanings are created and modified through an interpretive social process.

The hijab serves as a means of social interaction and has visual and verbal meaning.

Goffman (1959) claims that there is a separation in the Moslem woman's world, and that her world is divided into two spaces: a private and a public space. The private space exists with her family, her husband, etc., and there she can dress as she likes. The public space imposes on her wearing the hijab to achieve a conservative interaction with others. Accordingly, wearing the hijab symbolizes the border of the space between her and the public space.

Wearing the hijab has different meanings in different parts of the world. In certain areas, the hijab represents identity and belonging to a certain ethnic group. In addition, wearing the hijab may mean something different to the one wearing it and the one observing it. The woman wearing it is preserving a space of purity, piety, and honour; while the one observing it can give it various interpretations, though he would normally see it is as drawing the border line for Moslem woman in relation to their interaction with others (Alvi et al. 2003).

The stereotypical conception that women wear the hijab because of oppression by males is incorrect, and most research rejects this claim. Since the events of September 11, 2001, Moslem women and their hijab have become a stigmatic symbol in Western society; a symbol linked to radical Islam (Badr 2004: 335). This assumption is not correct, and does not reflect reality according to Western studies such as (Ali 2005: 517, Alvi et al. 2003, Al Wazni 2015). These studies claim that wearing the hijab does not reflect extreme religiosity, but that Moslem women in Western countries wear the hijab to create a cultural and social space for themselves. It is actually an attempt to help them build an identity in reaction to the society in which they live, to show that the hijab does not represent a radical religious Islamic conception, and that Islam is not evil or threatening.

Other researchers (Williams and Vashi 2007, Rinaldo 2013) explain that Moslem women wear the hijab deriving from free choice, and nobody forces them to dress like that. Respect is a central component in their feelings, and they get a lot of appreciation from others around them (Droogsma 2007). Still other researchers claim that the hijab forms a kind of protection that allows women to move in the public space without being criticized. The hijab also improves women's communication in mixed workplaces, signalling to men that they cannot gossip about them or view them as sexual objects, and that the Moslem woman is not open to contacts (Omair 2009, Bullock 2002: 103). In other words, the hijab acts as a requirement from others as to how they should behave. 
On the other hand, others (Gurbuz and Gurbuz-Kucuksari 2009, Al Wazni 2015) claim that hijab-wearing among academic Moslems in the USA frees them from the oppressive "beauty culture" of America, and from the unnecessary male gaze that follows them (Alvi et al. 2003; Bullock 2002) claim that wearing the hijab forces others to focus on women's personality rather than their sexuality.

In general, it is possible to say that the hijab creates a kind of a line of behaviour in the spirit of Islam; hijab-wearing women will always be under close scrutiny to test if their behaviour fits the spirit of Islam.

The question asked by many researchers is why Moslem women in Western societies wear the hijab even though there is no pressure on them to do so and they can dress as they wish. The answer can probably be found in multiculturalism and the various issues that allow them to present their identity in the social space without worry (Ali 2005). Therefore, it seems credible to claim that wearing the hijab is more an expression of their self and not of the society in which they live.

Figure 1. Reasons for Wearing the Hijab

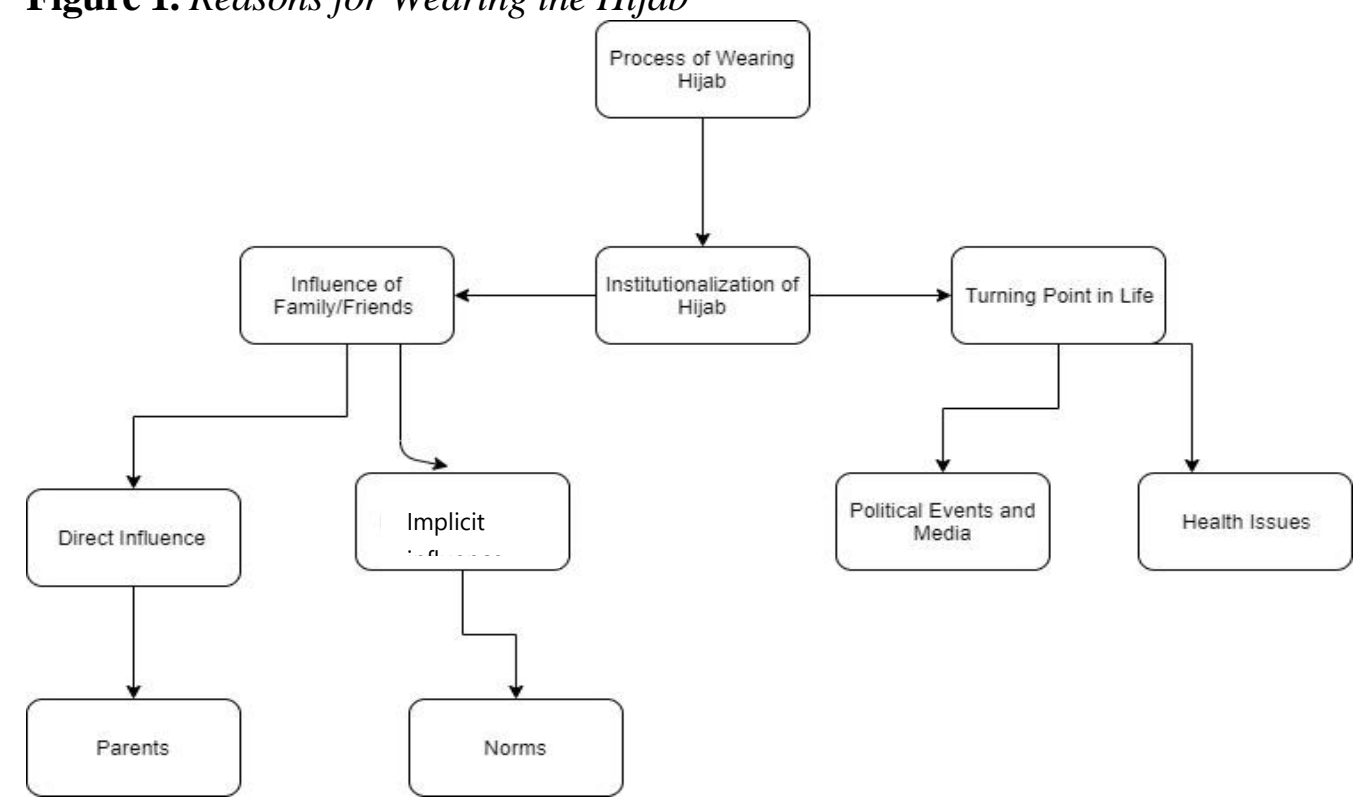

\section{Hijab and the West}

The topics of Islam, fundamentalism, terrorism, extremism, and women's status preoccupy the minds of a considerable number of scholars. The common mainstream discourse in the public domain talks about backwardness, violence, and barbarianism. As for the oppression of women, it is taken for granted. The situation was gradually further aggravated by various events in the Arab world towards the end of the twentieth century (Bullock 2011, Abdurraquib 2006, Unkelbach et al. 2010). This paper confronts the Western stereotypical image of the hijab as a symbol of oppression of Muslim women -a veritable uphill battle!

As for Muslims living in the West, there is an urgent need to change the 
negative stereotypical image of the hijab as a manifestation of oppression. There are cases that scientifically and objectively proved that Muslims are harmed by the negative perceptions of the hijab and Islam. In 1995, a number of Muslim female students were expelled from their schools in the province of Quebec in Canada because they refused to take off their hijab. A hijab-wearing teenager studying at a school in Quebec felt greatly humiliated when her schoolteacher announced on television that Islam degraded women. The girl said in response to her teacher's announcement: "I do not understand why any person says such a thing. She knows me and knows my personality. I am not like what she says." In 1997-8, many cases were documented of hijab-wearing women being expelled from their workplaces because of their headdress. This happened at a Dunkin' Donuts in Boston, in the Boston Market Restaurant, and at the Sheraton Hotel, Washington, in 1997 (Council on America Kelly Islamic Relations 1998, Bartkowski and Reed 2003, Droogsma 2007, Pasha-Zaidi 2015).

In Israel, a lecturer at Bar Ilan University asked a Muslim student to remove her hijab; when she refused, she was expelled from class (Ya'il Oom, News 29/10/2017). The same happened with a medical student when she was detained for a short period for wearing the hijab.

I do not wish in this research to follow up on all these cases, since this is not the purpose of the study. But in summary, based on these incidents, it may be concluded that the West expresses aggressive views toward the hijab and those who wear it, as well as associating it with the concepts of oppression and terrorism.

In a study conducted by Katherine Bullock (2002), "Western view of Hijab", interviews with a number of women in Toronto, Canada were conducted. It was found that the hijab is a religious outfit and not a form of oppression. In fact, it is part of a religion that gives dignity and respect to Muslim women. The public image of the hijab does not reflect the experience of women wearing hijab. The misrepresentation of the hijab always served Western politics, and continues to do so in the $21^{\text {st }}$ century. The association of the hijab with oppression is based on a Western view of the concepts of equality and freedom. Such established views obstruct other ways of understanding equality and freedom. Bullock concluded that Western culture is radically biased against Islam and Muslims, and that the media plays a central role in propagating a negative view of the hijab.

\section{Academic Education in Israel}

Israeli society consists of different ethnic and religious groups. There is a big difference between Jews and Arabs with regard to religion, language, lifestyle, and national aspirations (Jabareen 2005). Israeli Arab society is characterized by deep chasms between those who desire to integrate while preserving traditions and customs, and those who wish to head towards Western concepts and integration into Western culture. Different researchers (Herzog 2004, Jabareen 2005) showed that the younger generation has wished to emancipate itself and integrate into Western culture from the establishment of the State until the present time. 
The number of girls who seek university education, especially at teacher training colleges, has increased (Addi-Raccah 2006). The majority of Arab female students study at mixed Arab and Jewish colleges. However, there are two colleges (Qasimi and Sakhnin) where only Arab students learn. The total number of students studying in teacher training colleges in Israel is 26,320. Of this, $10 \%$ are Arab females, and $4.6 \%$ are Arab males, making a total of $14.6 \%$ of Arab students (Higher Education Council 2017).

This research focuses on the issue of the hijab worn by Arab female students who study at teacher training colleges. The research addresses the following question: How do Arab female students view the issue of wearing the hijab, and what are the mechanisms they use to adapt to their situation at these institutions? Since those students spend most of their time in the public domain rather than the private one, wearing the hijab makes the challenge of adapting and integrating more formidable.

\section{Research Methodology}

This research deals with a sample of female students studying in teacher training colleges, focusing on those wearing the hijab. It was noted that the forms of hijab they wore are varied and different. The research focuses on how these students view the hijab and what is the accepted perception with regard to the hijab. The research methodology is qualitative.

\section{Research Tools}

This research is based on in-depth interviews; the purpose is to identify how the female students view hijab. Analysis of interviews depends on the girls' stories with regard to the hijab. This methodology is important and appropriate for qualitative research; it helps to reveal the truth, understand the positions of those interviewed, and give it a deeper meaning. The interviewees each talk at length about her story (Lieblich et al. 1998). By using the method of in-depth interview or story, the researcher gets a deeper conception and understanding with regard to his/her attitudes and understanding of it (Polkinghorne 1995). Analysis of interviews (stories) enriches the research with a better understanding of the phenomenon in a deeper and more objective manner (Stake 2006).

\section{Participants}

In this research, 25 female students from two different colleges were interviewed. Some study at an exclusively Arab college, while others are enrolled at a mixed Arab and Jewish college: 10 and 15, respectively. All the respondents wear the hijab and their ages are between 18-26 years old. Five of them are 
married. All of them are seeking an educational diploma to become teachers.

\section{Research Question}

How do Palestinian university female students justify their choice of wearing the hijab?

\section{Research Significance and Procedures}

The topic has been a matter of fascination for me for some time. When the researcher was at a conference in the United Kingdom, during the discussions, the researcher noticed an Arab woman wearing the hijab and at the same time drinking a glass of wine. When the researcher asked her about it, she said the following, "My hijab reflects my identity rather than my religion." I do not think that this statement can be generalized, but it is an important indicator and an important gesture on the role of hijab. Furthermore, the research topic emerged out of a discussion in one of the courses the researcher teaches (analysis of events) where hijab-wearing students and non-hijab-wearing students discussed the religious aspect of the hijab. This increased the interest of both the researcher and the students to examine how female students viewed the hijab, its importance, and reasons for wearing it.

The researcher asked all female participants in this course to write an anonymous report on how they viewed the hijab and the reason why they wear it. Following a review of their written answers, it was found that the female students wrote about different aspects, including social, economic, and political ones, and not only the religious aspect. Their answers were general and did not provide indepth answers. The female students were asked whether they were willing to participate in the research fifteen female students out of 35 gave their consent. In the second college, in a classroom discussion on democracy, culture of dialogue, and the hijab, some female students expressed their willingness to gain a better understanding of the phenomenon, so the number of those who chose to take part in the research was 10 out of 40 female students. Ultimately, a total of 25 hijabwearing women from both colleges were interviewed in this research.

\section{Research Ethics}

The significance, objectives, and mechanisms of research were explained to the participants. The researcher further committed to keeping the names of both students and colleges in strict confidence. Interviewees were given the opportunity to read the transcripts of their interviews and hear the researcher's opinion about them. The researcher also made it clear that interviewees were free to withdraw from the research at any time. The voices of the interviewees were not recorded, to preserve their confidentiality and observe Arab customs and traditions. Interviews 
took place at regular research facilities at the colleges, during class breaks. Each interview lasted for half an hour and all interviews were conducted during one semester of the academic year 2017-2018. All students remained in the research group throughout, except for one student who withdrew for personal reasons that were not explained to the researcher.

\section{Interviews}

To draw close to the research population, we choose the technique of the interview, a technique that is considered the most successful for gathering a largest quantity of data on a topic. It is one of the best techniques for anyone wishing to explore the deep incentives of an individual, as well as identify the common reasons for their behaviour through the exclusive nature of each case (Lieblich et al. 1998). We adopted the focused individual interview, which required the researcher to prepare an interview guide incorporating aspects related to the topic. Interviews were then directly conducted with the respondents; namely, hijabwearing university students. This approach helped the researcher to be introduced to each woman so as to determine the way she interacts, speaks, and behaves. In this manner, we were able to explore the research subjects directly. Twenty-five official interviews were conducted with hijab-wearing university students during the academic year 2017-2018.

\section{Data Analysis}

The results were analysed according to the main classifications identified based on respondents' interviews.

\section{Prevalence of Fashion and Modernity}

It was found that Palestinian university female students have different attitudes towards wearing the hijab. The role of fashion in wearing the hijab is stronger than that of the religious/traditional aspect. The hijab-wearing university student is no longer someone who is an outsider, out of fashion, or oblivious to what is new. This happened as a result of the large-scale spread of fashionable clothes in window shops, magazines, and other types of mass media. During the interviews, it was found that the majority of students choose the fashionable hijab, and they now follow a fashion culture that requires them to be articulate in all the trademarks and brand names as well as fabric and quality of the cloth. Many of the students indicated that they have Turkish hijabs. Another student indicated that she was a member of a Facebook group where there was a lot of chatting and exchange of information about the importance, role, type, trademark, and quality of brands in the hijab market. Another student claimed, "There are clear boundaries 
that show the girl where she is allowed to be. The hijab came and allowed me to go places I was not allowed to go in the past. The society looks at the hijab as protecting a girl from harassment."

The results showed that wearing the hijab is considered a cultural value and symbol, which carries one of the dimensions of identity. The hijab was a form of religious and moral behaviour before it acquired a social dimension. It expresses holding fast to identity. However, the presence of girls in Jewish/Israeli society (essentially a Western society) and the question of globalisation have greatly contributed to changing the shape of the hijab to match fashion. Thus, a few students explained that the hijab is a personal freedom, and fashion paved their way towards choosing to wear hijab. One student explained this by saying the following: "A month ago, I went to Nablus and stopped before a window shop. I was wearing the traditional hijab. What interested me was that there were so many types of the hijab that go along with modern fashion. Since then, I have worn the hijab according to fashion, and I do not think this contradicts our religion."

\section{Religious Issues}

A few students wearing the traditional hijab indicated that the reason for the hijab is deep religious conviction. One of them indicated, "I started reciting the Quran and deeply reading the prophet's life story; after that I started to wear it."

\section{Influence of Families/ Friends (Society) Space and Identity}

Some students indicated the importance of values and traditions in wearing the hijab. One of the respondents indicated: "I was obligated by my dad and grandfather to wear the hijab. Sometimes when I travel with my friends, I take it off; then I wear it when I return home." Some respondents indicated that the hijab helps them to move around since the concept of the hijab means more respect and less harassment. "It warns others not to come near me or touch me. This convinces parents that their daughter is respected, and no one dares to harass her, for the hijab protects her."

One 20-year-old single student said, "I wear the hijab because most of the time I am in non-Moslem company, it's important to me to be seen as special; for me it's more an identity than a religion". Another student said: "The hijab gives me space, and also allows me to integrate into foreign societies, without fear of being hurt or absorbing Western norms". It also helps freedom of movement, as a 19-year-old student said: "The hijab allows me to get to college for my studies without having an escort such as a parent or a brother".

A 22-year-old single student explained the importance of family: "I didn't wear the hijab before, but once I wore it, I felt that both my closer and wider family are pleased and proud of me. It is important to me that my parents be happy." A married student mentioned another aspect: "In my nuclear family I didn't wear the hijab. But when I got married, my husband asked me to wear it, and so I did." 


\section{The Political Event and the Media}

Some respondents indicated that whenever they go to Jewish places, they take off the hijab to avoid inspection, racism, or humiliation. Two respondents said that they take off the hijab whenever they pass through Israeli military checkpoints because they are afraid of soldiers. Another student claimed that she was very much influenced by television shows especially the hijab news anchors on the Al Jazeera TV channel. In this way, she can abide by religious norms while also following the latest fashions.

Many students indicated that audio-visual media have an influence on their wearing of the hijab. Students indicated that religious satellite channels had a great effect on the practice of wearing the hijab. Two students indicated that the Egyptian Muslim preacher Amr Khalid played a major role in influencing girls to wear the hijab.

\section{Marriage Issues}

Girls wear the hijab as an important factor to speed up their prospects for marriage. Two students supported the idea that the hijab contributed to speeding up their marriage. The majority of young Arab men come from conservative families; therefore, they prefer hijab-wearing women. Some girls resort to the hijab only when they reach a certain age. Some of the respondents explained that the girl who wears the traditional hijab has a better chance for marriage; more than those wearing the Turkish hijab. The social pressure and fear of being left behind play an important role.

One girl related that a member of her family had been engaged to a girl from the north. When her family learned that the bride-to-be had recently removed the hijab, they broke off the engagement. Another hijab-wearing girl said that her hijab gives the impression that she is not too demanding in terms of wedding garments and preparations.

\section{Health Issues}

Two students made a connection between the hijab, health, and death issues. They said that a disease like cancer, as well as death, brought them closer to religion and to wearing the hijab because they believe it would protect them from such situations. One student said: "In my family there are two women who had cancer. Together with the disease came the hijab because it is important for them to be close to god and to be believers. I think all the time that perhaps the hijab cures the cancer". 


\section{Summary of Results}

The results above were translated in a graph (see Figure 2) that describes the different classifications for the respondents' interviews.

Figure 2. Respondent Classifications

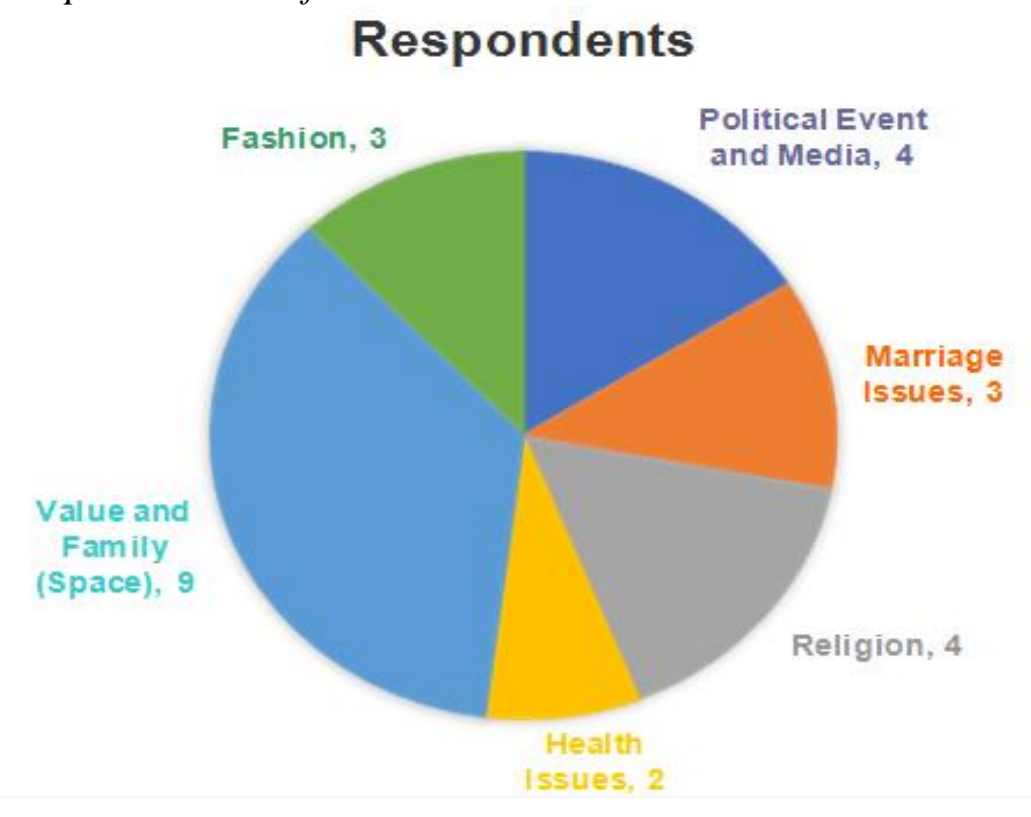

\section{Conclusion}

This research discussed the concept of the hijab and its meaning to "Palestinian Female University Students" in Israel. Wearing the hijab in the last two decades has become a popular phenomenon locally and globally; however, "to what extent do Muslim women need to cover up" is a debatable question among scholars as well as participants. The hijab holds multiple meanings for Muslim women.

Many of the current local and international views consider the hijab as a religious indicator only, and as reflecting the submission of women and an imposition of an oppressive policy upon them. However, the results of this study of the phenomenon of wearing the hijab among Arab Palestinian university female students in Israel, and the ways they viewed the hijab, showed clearly that the majority of the hijab concepts are not only religious.

The findings point out that the majority of students (9) wear the hijab as a result of the cultural and family values as the main factors, rather than a direct influence of religion. It should be noted that in many cases there is a distinction between the religion and the cultural values within Moslem society, and in many cases the weight of the cultural values is greater than that of the religious ones. In some cases, there is a contradiction between religion and culture. To demonstrate this, I bring an example that explains the contradiction. In the case of marriage, Islam encouraged marriage outside the extended family. But culture came up with a different approach, indicating that marriage should take place within the family. 
Therefore, in many cases, the effect of social values is greater than the impact of religion.

The hijab is a manifestation of some of the psychological and social pressures on university girls who belong to a segment of society trying to reconcile the contradiction between two kinds of concepts and values. On the one hand, there are traditional concepts that they inherit or acquire culturally, and on the other, the newer concepts supported by scientific and technological developments. As university students, they seek social acceptance, and work on proving their presence and social status that distinguishes them as intellectual elite. The hijab does not cancel their personality, nor does it confine their freedom. One of the interviewees stressed this by saying: "Eat as you wish, but dress how others wish to see you." Therefore, the students think that the hijab harmonizes with the environment and allows for integration into the society. It goes alongside fashion on one hand, and religion on the other. In Arab Palestinian institutions in Israel, we have noticed a new hijab culture nowadays -a youth culture that focuses on thought and behaviour, such as consumption habits and trademarks. Fashion culture (i.e., the modern hijab) has noticeably spread among Arab girls via the mass media and cultural gatherings and contexts within a Western society, such as Israeli society and their place of learning on university campuses.

The hijab constitutes one of the students' psychological and social needs, and it is a cultural expression that distinguishes between men and women in Muslim society. It evolves according to the changing social, cultural, and economic conditions. In light of the distinctiveness and nature of the female body, Islam obligated women to wear the hijab due to social, psychological, and religious as well as aesthetic values. This latter value prevails nowadays among female Palestinian university students in Israel. Undoubtedly, the university female student sees the modern hijab as a strategy to hold fast to the Islamic religion and to please the family on one hand, while appearing in an elegant and beautiful light on the other hand. It also helps her to move about, easily and freely.

Finally, the hijab plays a significant role in attracting a future life partner, especially when the girl reaches marrying age. She then resorts to wearing a hijab as a means to avoid becoming a spinster.

There is no doubt, therefore, that the prevailing idea about the hijab in the Western world which claims that the hijab is a means of oppression, terrorism, and piety is basically a misconception. The hijab has become a means used by young women to attract admiration and attention of others, as well as to show that they are different. The Arab Palestinian female student expresses her freedom and independence in her tastes and choices, sometimes by escaping stereotypes and traditions, and by following values and standards which scientific and media developments advocate. Therefore, the model of the Palestinian university female student in Israel expresses her personality, piety, thoughts, desires, motives, and justifications at the same time.

Based on our findings, the idea of the religious and traditional hijab as seeking to detach the woman from strangers by using restraints that inhibit the woman from participating in public life is now obsolete. The introduction of the Arab 
Palestinian hijab-wearing student in Israel into the academic, scientific, and university life has made it impossible to impose any restraint. Rationality stresses that the woman's honour, chastity, and virtue are not protected by locking her up within four walls. The model of the Palestinian university female student wearing the hijab is the best example of a Muslim woman's ability to adjust to a complex society by succeeding in establishing harmony between what is religious and worldly, and what is old and new.

\section{References}

Abdurraquib S (2006) The Hijab Scenes: Muslim Women, Migration and the Hijab in Immigrant Muslim Literature. MELUS 31(4): 55-70.

Abu Rabia-Queder S (2006) 'They Felt I Stole a Role Not Supposed to Be Mine': First Female School Principal in a Bedouin Tribal Society. In Women Principals in a Multicultural Society, I. Oplatka \& R. Hertz-Lazarowitz (ed), 74-81. The Netherlands: Sense Publishers.

Addi-Raccah A (2006) Women in the Israeli Education System. The Netherlands: Sense Publishers.

Ajrouch KJ (2007) Global Contexts and the Veil: Muslim Integration in the United States and France. Sociology of Religion 68(3): 321-325.

Al Akhras M (1967) The Hijab and Liberation. In Composition of Arab Family. Publications of the Ministry of Culture. Syria. [in Arabic].

Al Hufi N (2006) Report on Cairo and the Hijab. Amman website. Jordan.

Al Wazni A (20150 Muslim Women in America and Hijab: A Study of Empowerment, Feminist Identity, and Body Image. Social Work 60(4): 325-33.

$\mathrm{Al}$ Zuhairi M (2006) Hijab between Free Women and Slave Women. Tanweer website.

Ali S (2005) Why here, Why Now? Young Muslim Women Wearing Hijab. The Muslim World 95(4): 515-530.

Alvi S (2003) The Muslim Veil in North America: Issues and Debates, Homa Hoodfar and Sheila McDonough (eds). Toronto, ON: Women's Press.

Badawi J (1995) Gender Equity in Islam: Basic Principles. Plainfield: American Trust Publications.

Badr H (2004) Islamic Identity Re-Covered: Muslim Women After September 11th. Culture and Religion 5(3): 321-338.

Bartkowski JP, Read JNG (2003) Veiled Submission: Gender, Power and Identity among Evangelical and Muslim Women in the United States. Qualitative Sociology 26(1): 71-92.

Blumer H (1962) Society as Symbolic Interaction. In Human Behavior and Social Processes, AM Rose (ed), 179-92. Boston: Houghton Mifflin Co.

Bullock K (2002) Rethinking Muslim Women and the Veil: Challenging Historical \& Modern Stereotypes. International Institute of Islamic Thought.

Bullock K (2011) Western View of Hijab. Abu Dhabi. UAE. [in Arabic, translated by Shucri Mujahid]

Droogsma RA (2007) Redefining Hijab: American Muslim Women's Standpoints on Veiling. Journal of Applied Communication Research 35(3): 294-319.

Faisal T (2004) When Will Arab Women Ever Be the Trojan Horse? Al Jazeera website.

Goffman E (1959) The Presentation of Self in Everyday Life. New York: Anchor Books.

Gurbuz MG, Gurbuz-Kucuksari G (2009) Between Sacred Codes and Secular Consumer Society: The Practice of Headscarf Adoption among American College Girls. 
Journal of Muslim Minority Affairs 29(3): 387-399.

Higher Education Council in Israel 2017. Jerusalem, Israel.

Ibn M Tongue of Arabs. Lisãn al-Arab.

Jabareen Y (2005) Law, Education, and Social Change: The Case of Palestinian Arab Education in Israel. In Indigenous and Minority Education, D Champagne, I AbuSaad (eds), 107-135. Beer Sheva: Ben Gurion University of the Negev.

Khan ZH, Watson PI, Habib F (2005) Muslim Attitudes toward Religion, Religious Orientation and Empathy among Pakistanis. Mental Health, Religion and Culture 8: 49-61.

Khazal S (2006) Hijab between Manifestation and Belief. Social Studies Journal 18.

Latifi A (2006) A Reading of Hijab Phenomenon in Tunis. Al Jazeera website.

Liebleich A, Tuval-Mashiach R, Zilber T (1998) Narrative Research: Reading, Analysis and Interpretation. Thousand Oaks, CA: Sage

Mahfoodh H (2008) The Hijab in the Eyes of Little Muslim Women. Unpublished thesis. Graduate College of Bowling Green, Ohio.

Mussap AJ (2009) Strength of Faith and Body Image in Muslim and non-Muslim Women. Mental Health, Religion, and Culture 12: 121-127.

Omair K (2009) Arab Women Managers and Identity Formation through C Clothing. Gender in Management 24(6): 412-431.

Pasha-Zaidi N (2015) Judging by Appearances: Perceived Discrimination among South Asian Muslim Women in the US and the UAE.'J Int Women's Stud. 16: 70-97.

Polkinghorne D (1995) Narrative Configuration in Qualitative Analysis. International Journal of Qualitative Studies in Education 8(1): 5-23.

Radwan Z (1984) Phenomenon of Hijab. [Field research]. National Center for Social Research and Criminal Law, Cairo.

Rinaldo R (2013) Mobilizing piety: Islam and Feminism in Indonesia. Oxford University Press.

Shawish M (2002) The Hijab: A Fake Problem and Common Mistakes. Al Khaima Al Arabia website.

Stake RE (2006) Multiple Case Study Analysis. New York, NY: Guilford.

The Holy Qur'an

Williams RH, Vashi G (2007) Hijab and American Muslim Women: Creating the Space for Autonomous Selves. Sociology of Religion 68(3): 269-287.

Unkelbach C, Schneider H, Gode K, Senft M (2010) A Turban Effect, Too: Selection Biases against Women Wearing Muslim Headscarves. Social Psychological and Personality Science 1(4): 378-383.

Velasco Gonzalez K, Verkuyten M, Weesie J, Poppe E (2008) Prejudice towards Muslims in the Netherlands: Testing Integrated Threat Theory. British Journal of Social Psychology 47(4): 667-685.

Witkowski TH (1999) Religiosity and Social Meaning in Wearing Islamic Dress. Proceedings from the $7^{\text {th }}$ Cross Cultural Research Conference, Cancun, Mexico. 
